\title{
The Changing Paradigm in Sour Gas Treating Processes
}

\author{
Madhusree Kundu* \\ Department of Chemical Engineering, National Institute of Technology, India
}

Submission: September 18, 2017; Published: September 22, 2017

*Corresponding author: Madhusree Kundu, Department of Chemical Engineering, National Institute of Technology, Rourkela, Orissa, India, Email: mkundu@nitrkl.ac.in

\section{Mini Review}

The sour gas treating is the removal of hydrogen sulfide $\left(\mathrm{H}_{2} \mathrm{~S}\right)$, carbon dioxide $\left(\mathrm{CO}_{2}\right)$, and organo sulfides from gases. It is a common unit process used in refineries, and is also used in petrochemical plants, natural gas processing plants, and other industries. Currently, removal of carbon dioxide from thermal power plant flue gas seems to be a great challenge as well, which generically is different from natural gas and refinery off gas treating technology. Before chronicling the technologies and their changing spectrum in sour gas treating, the author would like to have a brief opportunity to discuss simply the plight of non-treating of sour gas. The $\mathrm{CO}_{2}$ enriched gas is having greenhouse effect and global warming potential, untreated hydrogen sulfide may corrode the pipelines in downstream processing, untreated gas incurs the reduction in fuel value of the gas. In LNG (liquefied natural gas) plants, $\mathrm{CO}_{2}$ should be removed to avoid freezing in the low temperature chillers. Moreover, in the manufacture of ammonia, it would poison the catalyst. The drastic change in climate has triggered an imbalance in ecology, socio-economic structure, energy security and sustainable development. CO2 emission, being one of the exponential components behind this changing climate and that has challenged the environmental poise. Carbon dioxide $\left(\mathrm{CO}_{2}\right)$ capture and sequestration or utilization (CCS/ $\mathrm{CCU}$ ) has taken the centre stage globally due to the increasing adversaries of $\mathrm{CO}_{2}$ emissions.

Among the most widely practiced gas treating processes, absorption into physical solvents or chemical solvents, and hybrid solvents (blends of chemical and physical solvents) have been the major ones [1,2]. Propylene carbonate (in Flour process), Dimethyl ether of Polyethylene Glycol (in Selexol process), N-methyl-2-pyrolidone (in Purisol Process), Chilled methanol (in Rectisol process) are the physical solvents used for has treating. DIPA-sulfolane-water (40-40-20 wt \%) under the trade name Sulfinol D, MDEA-sulfolane-water (4040-20 wt \%) under the trade name Sulfinol M and many more hybrid solvents are in use for gas treating. Among the different technologies available for $\mathrm{CO}_{2}$ mitigation, capture of $\mathrm{CO}_{2}$ by chemical absorption is the technology that is closest to get implemented commercially. The technology was patented for natural gas sweetening as early as 1930 by R.R. Bottoms [2]. Triethanolamine (TEA) was the first alkanolamine commercially available and used in early gas-treating plants. In the present context, the role of alkanolamine solvents in sour gas treating research should be revered. Chemical absorption processes for gas treating may be divided into three conceptual categories distinguished by the rate at which the solvent reacts with $\mathrm{CO}_{2}$. The first group of processes can be termed "bulk" $\mathrm{CO}_{2}$ treating processes, and are well-known by their ability to remove $\mathrm{CO}_{2}$ to very low levels. Aqueous primary or secondary alkanolamines and promoted hot carbonate salts are prominent solvents in this category. Though the reaction of $\mathrm{CO}_{2}$ with these alkanolamines is fast, it is accompanied by a highly exothermic heat of reaction [2], which must be supplied in the regenerator to regenerate the solvent. Consequently, these processes can be energy intensive [1]. The second group of processes employing tertiary or hindered alkanolamines to avoid the faster carbamate formation reaction represents the second group of "selective" treating processes. These selective processes are capable of removing as much as $90 \%$ of the $\mathrm{CO} 2$ in the feed gas while removing H2S to very low levels (less than $4 \mathrm{ppm}$ ) [2]. The tertiary alkanolamine MDEA can be regarded as a selective treating agent. A third category of processes is selective treating category. Blended alkanolamines and sterically hindered alkanolamines (2-amino-2- methyl-1propanol (AMP), 2-amino-2-(hydroxymethyl)-1, 3-propanediol (AHPD)) are suitable candidates of this category, which reduces the regeneration energy requirement for the recirculating solvents. Solvent loss, high capital investment for absorbers and strippers, high regeneration energy requirement of alkanolamines have necessitated still better solvent formulation suitable for large scale industrial process applications. 


\section{Recent Advances in Petrochemical Science}

Gas treating research has witnessed several transitions. Room temperature ionic liquids (RTL's) and their mixtures with alkanolamines, alkali metal salts of a number of tertiary amino acids promoted with reactive amines such as MEA have been used in $\mathrm{CO}_{2}$ absorption. Some solvents have been proposed with multiple amine functionalities and among them, Piperazine (PZ) has been used as a promoter specially in treating coal based power plant flue gas [3]. The molecular structure and spatial arrangement of the attached functional groups in alkanolamines may be crucial in $\mathrm{CO}_{2}$ absorption $[4,5]$. Apart from absorption, adsorption (Solid Surface), and physical separation (membrane, cryogenic Separation) process have been used in sour gas treating. Paul et al. [6] have studied theoretically the absorption of carbon dioxide in different single and blended alkanolamine solvents using flat sheet membrane contactor (FSMC). Wang et al. [7] have studied the absorption of $\mathrm{CO}_{2}$ into water using parallel-plate gas-liquid membrane contactor. The largest membrane based natural gas processing plant in the world is located at Qadirpur, Pakistan (Dortmundt, UOP, 1999). Process integrated membrane and absorption unit are advantageous because of reduced size of membrane gas liquid contactors and weight, wide range of liquid and gas flows, lower capital costs, reduction in energy (if membranes are integrated with the stripping unit), reduction in solvent losses, no entrainment, flooding or channeling. The fascinating facts could not be transformed in to a full flagged, commercially viable $\mathrm{CO}_{2}$ capture technology at large scales. The real issues are low selectivity \& flux - large scale systems not economically viable (yet), thermal stability of polymer membranes, degradation \& lifetime of membrane, and immature technology.

Commonly used adsorption processes are; the iron oxide, zinc oxide, MOFs and molecular sieve (zeolite) process. In recent years, there has been considerable research on the use of zeolites, metal organic frameworks (MOFs), and zeolitic imidazolate frameworks (ZIFs) for selective adsorption of $\mathrm{CO} 2$ from $\mathrm{CO}_{2} / \mathrm{H}_{2}, \mathrm{CO}_{2} / \mathrm{CH} 4$ and $\mathrm{CO}_{2} / \mathrm{N}_{2}$ mixtures [8-13].

A promising novel option is to freeze out (desublimate) CO2 from flue gases using cryogenically cooled surfaces. High cooling costs could be minimized by exploiting the cold duty available at Liquefied Natural Gas (LNG) re-gasification sites. A novel process concept has been developed by [14], based on the periodic operation of cryogenically cooled and dynamically operated packed beds. An extensive R\&D effort has been envisioned towards conversion of $\mathrm{CO}_{2}$ to hydrocarbon by chemical, and biochemical routes, possibly it is one of the strategic routes leading to our future survival in this planet.

\section{References}

1. Astarita G, Savage DW, Bisio A (1983) Gas treating with chemical solvents. John Wiley and Sons, New York, USA.

2. Kohl AL, Nielsen RB (1997) Gas Purification ( $5^{\text {th }}$ edn), Gulf Publishing Company, Houston, USA.

3. Bishnoi S, Rochelle GT (2002) Absorption of carbon dioxide in aqueous piperazine / methyldiethanolamine. AIChE Journal 48(12): 2788-2799.

4. Chowdhury FA, Yamada H, Higashii T, Goto K, Onoda M, et al. (2013) CO2 capture by tertiary amine absorbents: a performance comparison study. Ind Eng Chem Research 52(24): 8323-8331.

5. Adak S, Kundu M (2017) Vapor-liquid equilibrium and physicochemical properties of novel aqueous blends of (2-Diethylaminoethanol + Piperazine) for $\mathrm{CO}_{2}$ appropriation. Journal of Chemical \& Engineering Data 62(7): 937-1947.

6. Paul S, Ghoshal AK, Mandal B (2008) Theoretical studies on separation of $\mathrm{CO} 2$ by single and blended aqueous alkanolamine solvents in flat sheet membrane contactor (FSMC). Chemical Engineering Journal 144(3): 352-360

7. Wang R, Li DF, Liang DT (2004) Modelling of CO2 capture by three typical amine solutions in hollow fiber membrane contactors. Chem Eng Proces 43(7): 849-856.

8. Chowdhury P, Mekala S, Dreisbach F, Gumma S (2012) Adsorption of CO, CO2 and CH4 on Cu-BTC and MIL-101 Metal Organic Frameworks: Effect of Open Metal Sites and Adsorbate Polarity. Microporous and Mesoporous Materials 152(1): 246-252.

9. Mishra P, Mekala S, Dreisbach F, Mandal B, Gumma S (2012) Adsorption of $\mathrm{CO}_{2}, \mathrm{CO}, \mathrm{CH}_{4}$ and $\mathrm{N}_{2}$ on a zinc based metal organic framework. Separation and Purification Technology 94: 124-130.

10. Mason JA, Sumida K, Herm ZR, Krishna R, Long JR, et al. (2011) Evaluating metal-organic frameworks for post-combustion carbon dioxide capture via temperature swing adsorption. Energy and Environmental Science 8: 3030-3040.

11. Krishna R, Baten JM (2007) Using molecular simulations for screening of zeolites for separation of $\mathrm{CO} 2 / \mathrm{CH} 4$ mixtures. Chemical Engineering Journal 133(1-3): 121-131

12. Krishna R, Baten JM (2011) Investigating the potential of MgMOF-74 membranes for $\mathrm{CO}_{2}$ capture. Journal of Membrane Science 377(1-2): 249-260.

13. Krishna R, Baur R (2003) Modelling issues in zeolite based separation processes. Separation and Purification Technology 33(3): 213-254.

14. Tuinier MJ (2011) Novel process concept for cryogenic $\mathrm{CO}_{2}$ capture. Ph.D Dissertation.Eindhoven University of Technology, Netherlands. 
This work is licensed under Creative Commons Attribution 4.0 Licens DOI: 10.19080/RAPSCI.2017.03.555608

\section{Your next submission with Juniper Publishers will reach you the below assets}

- Quality Editorial service

- Swift Peer Review

- Reprints availability

- E-prints Service

- Manuscript Podcast for convenient understanding

- Global attainment for your research

- Manuscript accessibility in different formats ( Pdf, E-pub, Full Text, Audio)

- Unceasing customer service

Track the below URL for one-step submission https://juniperpublishers.com/online-submission.php 